\title{
Bioética de Intervenção - uma proposta epistemológica e uma necessidade para sociedades com grupos sociais vulneráveis
}

\section{Intervention Bioethics - an epistemological proposal and a necessary tool to societies with vulnerable social groups}

\author{
Márcio Rojas da Cruz \\ Coordenação Geral de Biotecnologia e Saúde, Ministério da Ciência e Tecno- \\ logia, Brasília, Distrito Federal, Brasil. \\ mroias@mct.qov.br \\ Etelvino de Souza Trindade \\ Unidade de Ginecologia Oncológica, Hospital de Base do Distrito Federal, \\ Brasília, Distrito Federal, Brasil. \\ estrindade@brturbo.com.br
}

Resumo: O Brasil, país de grande desigualdade social, apresenta pequena parcela da população com acesso aos mais recentes avanços da tecnologia médica e grande parcela desta mesma população que vive a incerteza de uma possível refeição. Diante da situação de interação de fatores responsáveis por dificuldades diversas, desde os problemas mais caros do ponto de vista financeiro até os mais caros do ponto de vista da dignidade humana, a Bioética de Intervenção estabelece conceitos necessários para integrar ações concretas: bioética das situações emergentes e persistentes; países centrais e periféricos; ética e moral; eqüidade e igualdade; empoderamento, libertação e emancipação; e imperialismo moral. Como fundamentos, são elencados: a concentração de poder; a globalização; a finitude dos recursos naturais; a corporeidade, o prazer e a dor; os direitos humanos; os "4 Ps" (prudência, prevenção, precaução e proteção); a solidariedade crítica; e a responsabilidade. A Bioética de Intervenção impele ações de forma a almejar a diminuição das iniqüidades sociais por meio de práticas intervencionistas duras conforme sugere a denominação original desta corrente: hard bioethics.

Palavras-chave: Bioética. Bioética de Intervenção. Bioética "Dura". Vulnerabildade. Epistemologia.

Abstract: Brazil is a country of great social inequities, where just a small portion of the resident people have access to the most recent advances of medical technology. Moreover, a huge portion of its population is not sure about the possibility of having a meal. In face of this situation of interaction of factors which are responsible for many difficulties, the Intervention Bioethics establishes several concepts that are necessary for the integration of concrete 


\section{Revista Brasileira de Bioética}

actions. These concepts are: bioethics of emergent and persistent situations; central and peripheral countries; ethics and moral; equity and equality; empowerment, liberty and emancipation; and moral imperialism. As theoretical foundations, we may enumerate: the concentration of power; globalisation; depletion of natural resources; corporeality, pleasure and pain; human rights; the "4 Ps" (prudence, prevention, precaution and protection); critic solidarity; and responsibility. The Intervention Bioethics impels actions towards the reduction of social iniquities through hard practical interventions, as the very original denomination of this theoretical current suggests: hard bioethics.

Key words: Bioethics. Intervention Bioethics. "Hard"Bioethics. Vulnerability. Epistemology.

O Brasil é rico em diversidade, considerada a maior do mundo. Os biomas contêm acima de $20 \%$ do número total de espécies de seres vivos do planeta, com a mais alta taxa de endemismo. A diversidade cultural, por sua vez, resultante de fatores históricos singulares, permite a rica experiência da vivência concreta da pluralidade no dia-adia dos brasileiros.

Entretanto, não são encontradas apenas as diversidades "desejadas". Diversidades no grau de escolaridade, no acesso aos serviços básicos de saúde, no nível de renda familiar, são "indesejadas", e exigem combate por medidas que eliminem ou abrandem suas causas. Elas fazem do Brasil um país de profundos contrastes.

Entre 1975 e 2001 o Brasil cresceu em média 0,8\% ao ano; ascendeu dez colocações no ranking mundial nos anos 1970 a 1980, duas colocações na década de 1990; e outras quatro colocações a partir de 2000. Em que pese o fato de que desde 1975 o País também tenha apresentado Índice de Desenvolvimento Humano (IDH) com crescimento acima da média da América Latina, a análise em separado das dimensões educação, renda e longevidade, mostram que considerável parcela da população sofre com a falta de acesso a bens básicos para uma existência saudável (1).

O contraste mais grave é observado na concentração de renda. O parâmetro internacional empregado para aferir a concentração de renda é o Índice de Gini. Sua variação ocorre entre os valores " 0 " e "1", sendo que "0" representa a situação hipotética em que todos os 
cidadãos têm exatamente a mesma renda (igualdade perfeita) e "1" a situação hipotética em que toda a renda estaria concentrada sob o poder de apenas um único indivíduo (desigualdade absoluta). O Índice de Gini brasileiro é de 0,61, enquanto o mundial é de 0,66 . Os $10 \%$ de domicílios mais ricos - que concentram $46,9 \%$ da renda nacional - têm renda aproximadamente 70 vezes maior, quando comparados aos $10 \%$ de domicílios mais pobres, que detêm $0,7 \%$ da renda nacional (2).

Em se tratando de mortalidade infantil, encontra-se a surpreendente situação de redução da taxa nacional concomitante com o aumento da desigualdade entre crianças pobres e ricas. Entre as regiões brasileiras, a mais alta taxa de mortalidade infantil ocorre no Nordeste (aproximadamente 74\%o), enquanto no Sul existe a menor taxa (aproximadamente 27\%o), implicando um diferencial de 150\% (3).

O corolário de toda esta desigualdade social é que pequena parcela dos cerca de 170 milhões de brasileiros têm acesso, por exemplo, aos mais recentes avanços da tecnologia médica, como tomografia computadorizada e medicamentos de última geração, ao mesmo tempo em que grande parcela desta mesma população vive cotidianamente a incerteza relativa a uma possível refeição.

É nesse cenário que, a partir da década de 1990, a bioética surgiu como uma disciplina de forma orgânica para a sociedade brasileira. Seu nascimento se deu de modo cooperativo, como resultado da interação de diversas iniciativas isoladas. Os mais relevantes acontecimentos que contribuíram para o amadurecimento da bioética nacional, em ordem cronológica, são os seguintes: o periódico Bioética, a fundação da Sociedade Brasileira de Bioética (SBB) e a criação da Comissão Nacional de Ética em Pesquisa (Conep) (4).

O periódico Bioética, publicado pelo Conselho Federal de Medicina, teve seu primeiro número editado em 1993. A iniciativa buscava a reflexão e o debate das questões éticas no país, fomentando, produzindo e democratizando o conhecimento científico, com especial enfoque nas questões relativas à ética médica (5).

A Sociedade Brasileira de Bioética, criada em 1995, tem por objetivos: fomentar a discussão e a difusão da bioética; estimular a produção do conhecimento; promover e assessorar planos, projetos, pesquisas e atividades; patrocinar eventos; e apoiar e participar de movimentos e atividades que visem a valorização da bioética. Atualmente, con- 


\section{Revista Brasileira de Bioética}

ta com representações regionais em diversos estados brasileiros e já realizou seis congressos nacionais, sendo que o IV Congresso Brasileiro de Bioética, realizado em Brasília no ano de 2002, ocorreu em conjunto com o VI Congresso Mundial de Bioética da International Association of Bioethics (IAB) (6).

No ano de 1996, por meio da Resolução no 196, o Conselho Nacional de Saúde (CNS) estabeleceu as Diretrizes e Normas Regulamentadoras para Pesquisas Envolvendo Seres Humanos, e foi, então, criado o Sistema CEP/Conep. Cabe aos Comitês de Ética em Pesquisa (CEP) a responsabilidade primária sobre as decisões em pesquisas a serem desenvolvidas nas instituições às quais pertencem e à Comissão Nacional de Ética em Pesquisa o exame de aspectos éticos de alguns tipos específicos de pesquisa envolvendo seres humanos, bem como a adequação e a atualização das normas atinentes (7).

\section{Conceitos}

Em decorrência dos dados anteriormente expostos, percebe-se a necessidade de uma reflexão bioética direcionada para a realidade brasileira, que esteja adequadamente instrumentalizada para agir na busca de soluções para os obstáculos que impedem ou dificultam a existência de uma sociedade mais equânime. Diante da situação particular, observada na interação dos fatores responsáveis pelas dificuldades as mais diversas, desde os problemas mais caros do ponto de vista financeiro até os problemas mais caros do ponto de vista da dignidade da espécie humana, a Bioética de Intervenção vem estabelecendo, como alicerce, os conceitos necessários para a orientação de ações concretas.

Os dois primeiros conceitos, o de bioética das situações emergentes e o de bioética das situações persistentes, já foram introduzidos neste texto de forma não explícita. Eles são conceitos amplamente empregados entre pensadores da bioética latino-americana por refletirem a condição vivida na região. A bioética das situações emergentes lida com questões decorrentes do desenvolvimento biotecnocientífico vivido pelo mundo nas últimas décadas (8). Como exemplos, são citados os problemas que envolvem os estudos dos conjuntos de diversos componentes celulares (genômica, proteômica, metabolômi- 
ca, transcriptômica e suas variações e aplicações como a transgenia e a intragenia), as novas tecnologias reprodutivas e os transplantes de órgãos e tecidos com fins terapêuticos. Estes são problemas caros sob o ponto de vista financeiro. A bioética das situações persistentes, por sua vez, está vinculada às condições que se mantêm nas sociedades humanas desde a antigüidade (8). Como exemplos, a exclusão social, a pobreza e as diferentes formas de discriminação. Estes são problemas caros sob o ponto de vista da dignidade da espécie humana, que vergonhosamente protela medidas compensatórias para esses males.

Os próximos dois conceitos derivam da esfera das relações internacionais e foram assimilados e trabalhados pela Cátedra UNESCO de Bioética da Universidade de Brasília. Países centrais são todos aqueles em que os problemas básicos de saúde, educação, alimentação, moradia e transporte já estão devidamente resolvidos ou com soluções encaminhadas (8). Países periféricos são nações nas quais a maioria da população luta por condições mínimas de sobrevivência com dignidade e onde a concentração de poder e renda está nas mãos de um número reduzido de pessoas (8). Em outras palavras, os países centrais gozam do conforto de apresentarem, em sua agenda de discussão bioética, apenas uma parcela das situações emergentes, enquanto os países periféricos, além da discussão das questões emergentes, também necessitam discutir as questões persistentes. Ao expor a distinção entre países centrais e países periféricos do mundo contemporâneo, indica-se como fator sinérgico para a busca de resultados em bioética a cooperação regional dos países em condições similares, além de ser reivindicada a capacidade dos países periféricos em vir a se tornar centrais.

Diante das diversas formas que os termos ética e moral são usados nos textos de bioética, é importante esclarecer a exata idéia que têm os mesmos para a Bioética de Intervenção. Muitos autores empregam as palavras ética e moral como sinônimas. Ainda que ambos tratem do padrão ideal de comportamento para a otimização da vida social, a análise das raízes históricas destes dois termos confere um caráter mais abrangente para a idéia de ética, com qualidade de fenômeno universal e generalizável, enquanto a idéia de moral está relacionada com características de fenômenos culturais específicos, com valores de cada grupo social (9). Dessa organização de idéias se extrai que 


\section{Revista Brasileira de Bioética}

o debate ético precisa ir além da pluralidade moral, identificada e vivida por comunidades/grupos de pessoas que partilham os mesmos valores, para alcançar uma dimensão abrangente, que diz respeito às condições necessárias à existência física e social dos indivíduos, compartilhada por todos os atores envolvidos, com enfoque preferencial na eqüidade.

Os próximos dois conceitos já são contemplados em discussões no âmbito da saúde pública brasileira, estando presentes inclusive na legislação afeta ao tema. Pelo fato de não existirem sequer duas pessoas que sejam absolutamente idênticas (constatação esta bem demonstrada por experimentos com gêmeos univitelinos), fica claro que as pessoas têm necessidades diferentes para atingir objetivos iguais. A eqüidade nada mais é do que o reconhecimento dessas distintas necessidades para que todos gozem de uma vida com o maior grau de dignidade possível. Por sua vez, a igualdade pode ser definida como a conseqüência desejada da eqüidade, como o ponto de chegada para a justiça social (10). O exemplo da mortalidade infantil na introdução deste trabalho, refere-se a crianças nascidas na Região Nordeste brasileira, as quais têm chance significativamente menor de sobrevivência quando comparadas às nascidas na Região Sul. Trata-se de um exemplo indiscutível de cacotanásia - termo empregado por Berlinguer quando se refere às mortes ruins enquanto previsíveis e evitáveis (11) - e, por conseguinte, de desatenção ou de descompromisso com a eqüidade. Não existe nada que seja intrínseco ao organismo das crianças nordestinas ou sulinas que justifique tamanha diferença no índice considerado. Se ambos os grupos de crianças tivessem igual condição de vida e igual acesso aos serviços de saúde de qualidade, seguramente a mortalidade infantil verificada nas distintas comunidades seria similar.

O tópico justiça social deve ser desenvolvido um pouco mais em vista de sua importância para o debate bioético, especialmente em países periféricos obrigados ainda a lidar com questões persistentes. Assim, serão considerados três conceitos de certa forma inter-relacionados e proveitosos para a Bioética de Intervenção. O primeiro - libertação - ganhou notoriedade com o educador brasileiro Paulo Freire. O termo libertação vai além da constatação da relação com o poder e indica que existem forças opressoras atuando sobre pessoas/grupos 
sociais, que os tornam frágeis, com o exercício da autonomia cerceado pela coação. Por conseguinte, é revelada a necessidade de atuar solidamente no sentido da eliminar as forças opressoras e garantir os elementos essenciais para a cidadania, como saúde e educação (12). O segundo - empoderamento - ganhou notoriedade com o cientista indiano, ganhador do Prêmio Nobel de Economia, Amartya Sen. O empoderamento chama a atenção para o fato de que as escolhas autônomas não podem ser influenciadas por falta de opções e designa a outorga dos meios adequados às pessoas vulnerabilizadas de galgar o legítimo poder de decisão (12). O terceiro conceito relacionado à justiça social é o da emancipação. Apenas pode ser considerado emancipado o indivíduo com a dependência devidamente suprimida e com a sobrevivência devidamente garantida. Não basta assegurar a sobrevivência, mas também devem estar asseguradas as opções para que a sobrevivência seja alcançada (12). Definitivamente, a inclusão social é fator de peso nos considerandos da Bioética de Intervenção, com empenho de continuidade garantida, extrapolando para a dimensão política.

Por fim, um último conceito, imperialismo moral. Na ânsia de conquistar cada vez mais poder financeiro, percebe-se que a lógica capitalista imputada às nações é responsável pela transformação de sociedades em mercados. E, como em não raras vezes as moralidades das diferentes sociedades não são exatamente compatíveis com as práticas comerciais pretendidas pelos países economicamente mais fortes, elas (as moralidades) passam a ser tidas como obstáculos ao projeto de expansão desenfreada. E quando a resistência atinge um nível "inaceitável", implementa-se ou tenta-se implementar medidas impositivas, por meio das mais diversas formas de coação, de imposição de padrões morais específicos, de determinadas culturas, regiões geográfico-políticas e países, para outros, caracterizando o que a Bioética de Intervenção considera como Imperialismo Moral.

$\mathrm{O}$ imperialismo moral pode se dar de forma ativa ou passiva. É considerado imperialismo moral ativo quando ocorre o envolvimento de uma ação específica. Por exemplo, há alguns anos, certos países centrais não têm medido esforços para alterar o texto da Declaração de Helsinque, no que tange a questão do double standard. O objetivo por trás dessa empreitada, que se materializaria na flexibilização das 
normas para pesquisas com seres humanos, é acelerar ou baratear de forma irresponsável as pesquisas clínicas necessárias para a verificação da segurança e da ação terapêutica de novos medicamentos. Para que a indústria farmacêutica alcance maior lucratividade em menor espaço de tempo, há nações que imprimem, ainda que de forma velada, em alguns fóruns internacionais, o caráter de utilidade para vidas humanas vulnerabilizadas por um estado extremo de pobreza como meio para atingir tal fim. O imperialismo moral passivo envolve ato de omissão perante uma situação em que a ética universalizada não hesita em exigir uma ação. Por exemplo, o Tratado de Kioto é uma iniciativa internacional que busca o comprometimento dos países do globo terrestre em reduzir a emissão de dióxido de carbono no planeta até a primeira década do Século XXI. Este gás, produzido principalmente pela combustão de combustíveis fósseis, apresenta propriedades que geram o efeito estufa, pela retenção da radiação solar na atmosfera. Os Estados Unidos, ainda que responsáveis por aproximadamente $20 \%$ da poluição ambiental mundial, têm se negado terminantemente a assinar este importante tratado internacional (13).

Os conceitos expostos alicerçam a proposta da Bioética de Intervenção. Ainda que necessários, eles não são, per se, suficientes para garantir a devida sustentação argumentativa da Bioética de Intervenção. Por conseguinte, faz-se necessária a reflexão sobre a fundamentação desta corrente de pensamento bioético.

\section{Fundamentos}

Com o progresso científico e tecnológico e largamente influenciados pela mentalidade "dinheirocêntrica" que rege as relações comerciais, os grupos que deram os primeiros passos em direção à existência desenvolvida não hesitaram em utilizar dessa vantagem inicial para acentuá-la ainda mais. A exploração das inovações científicas e tecnológicas acabou por resultar em uma situação em que a distribuição da riqueza e, por conseqüência, o acesso aos recursos se tornaram inversamente proporcionais à divisão numérica da população. Em outras palavras, um pequeno grupo de comunidades centrais deteve o poder, enquanto o grupo maior das comunidades periféricas foi submetido às decisões alheias aos seus próprios interesses. Essa situação 
de concentração de poder possibilitou tentativas de dominação ideológica e moral por parte das comunidades centrais. Uma vez que a ciência e a tecnologia estão intimamente associadas à moralidade da sua produção, o processo de expansão econômica com base no domínio do conhecimento científico e tecnológico foi acompanhado por um processo de expansão da moralidade associada a este conhecimento (9). Previsivelmente, diante da pluralidade moral das comunidades, a imposição de uma moralidade hegemônica foi interpretada como ato agressivo por algumas comunidades, acabando por gerar conflitos.

O fenômeno da globalização possibilitou a transposição para a escala planetária desse cenário de concentração de poder. A prática econômica exercida em escala mundial deu origem não mais a comunidades centrais e periféricas, mas a países centrais e periféricos, intensificando a relação inversamente proporcional entre o número de pessoas e a distribuição de riqueza. Se a avaliação da diversidade moral já indicava uma pluralidade de grau significativo, com a globalização, a pluralidade moral se tornou enorme, dando espaço para verdadeiros abismos ao entendimento (9). De acordo com a proposição de que os fins justificam os meios, defendida pela lógica capitalista, os países centrais interpretaram como legítima a apropriação de recursos naturais e humanos dos países periféricos. Diante desse quadro de intensificação da concentração de poder e da constatação das diferenças quanto aos interesses econômicos e morais, os conflitos também foram intensificados e, em casos extremos, envolvendo lutas armadas.

Conscientes da extrema dificuldade em empreender diálogo conciliatório para os conflitos oriundos do aumento da área de atuação de uma moralidade particular, generalizando-a, a Bioética de Intervenção elegeu como fundamento relevante, a constatação por parte da comunidade científica, da finitude dos recursos naturais. Isso se deveu em parte ao alto grau da pluralidade envolvido e também pela forte influência econômica em questão. É notório que a espécie humana tem, especialmente da época pré-industrial até os dias atuais, provocado mudança no meio ambiente físico e biológico em que vive e do qual sua própria existência depende. $O$ dado mais alarmante a este respeito é a demonstração real do aumento da temperatura global. O efeito estimado do aumento da concentração de gases estufa na atmosfera terrestre, nos próximos 50 anos, aumentará a temperatura 


\section{Revista Brasileira de Bioética}

da superfície da Terra em cerca de 0,6 a 2,5 ${ }^{\circ} \mathrm{C}$ e, nos próximos 100 anos, o aumento será de aproximadamente 1,4 a $5,8^{\circ} \mathrm{C}(14)$.

$\mathrm{O}$ fato de os recursos naturais serem uma fonte de riqueza nãorenovável e, ainda, considerando que as conseqüências pelo rumo da evolução (no sentido biológico, de mudança, não necessariamente para melhor) da biosfera será compartilhada por todas as sociedades, independentemente de seus graus de responsabilidade pela mesma, exige que o alerta sobre a finitude dos recursos naturais deva ser apresentado de modo sólido, suficiente para que a arbitrariedade de posicionamento de alguns países centrais seja substancialmente flexibilizada (9).

É digno de nota que a preocupação com a continuidade da existência da espécie humana já estava presente nos primórdios da disciplina da bioética, podendo ser inclusive considerada como a maior motivação para sua criação:

"Uma ciência da sobrevivência deve ser mais do que uma ciência apenas, e eu, portanto, proponho o termo Bioética a fim de enfatizar os dois mais importantes ingredientes para se alcançar a nova sabedoria que é desesperadamente necessária: conhecimento biológico e valores humanos. Nesta época de especialização, nós parecemos ter perdido contato com os lembretes diários que provaram a verdade para os nossos ancestrais: o homem não pode viver sem cultivar plantas ou matar animais. Se as plantas secarem e morrerem e os animais falharem em se reproduzir, o homem adoecerá e morrerá e falhará em manter a sua espécie" (15).

Uma vez que a bioética está preocupada particularmente com a continuidade da existência da espécie humana e com a forma com que vai se dar essa existência, a eleição do fator corporeidade como marco teórico e conceitual para a Bioética de Intervenção, agrega à discussão dois indicadores importantes para a necessidade e a orientação da intervenção, o prazer e a dor.

"A defesa do reconhecimento da concretude humana advogada pela Bioética de Intervenção pauta-se na idéia de que qual- 
quer abordagem ou dimensão a partir da qual se analisa o ser humano será calcada, a priori, sobre o corpo humano; sobre suas interpretações que o senso comum e que cada área do conhecimento the conferem. Como veículo da existência física ele é o universal óbvio. Neste sentido, vale recordar que isso implica no reconhecimento da realidade física como determinante para qualquer elaboração sobre o real" (16).

Assim, é proposto o resgate da idéia de corpo, que transcende a limitação à dimensão fisiológica imposta pelo paradigma cartesiano, passando também a contemplar a dimensão social. As sensações de prazer e de dor seriam os pólos extremos do espectro das necessidades mais básicas das pessoas humanas, que ganham existência na experiência corpórea de cada indivíduo em suas relações com o meio social e com o meio ambiente (16).

Diante do exposto nesta seção e na anterior, ao se refletir sobre a distribuição da totalidade dos seres humanos, que vivem nesse espectro de necessidades delimitado pelas sensações de prazer e de dor, pode-se chegar à conclusão de que atualmente a humanidade está dividida em dois grupos desiguais. O primeiro grupo poderia ser considerado o da humanidade propriamente dita; a ele pertence a minoria da população mundial que tem a possibilidade da vida em plenitude com seus direitos de liberdade e igualdade devidamente assegurados. O segundo grupo seria considerado o da subumanidade, que corresponde a grande parte da população mundial; a esse grupo cabe uma existência de falta de segurança e de acesso às necessidades básicas.

Nesse cenário, é natural que sejam elencados também como parâmetro os direitos humanos. A concepção dos direitos humanos tem por base o princípio inquestionável de todas as pessoas - apesar das inúmeras diferenças que poderiam ser relacionadas - pertencerem à mesma humanidade e, por conseqüência, dever ser garantida a todos a inalienabilidade do direito à vida (9). A lucubração bioética deve vislumbrar os direitos humanos da mesma forma que os navegantes, ao empreenderem trajetórias desafiadoras, terem buscado nas estrelas as orientações para alcançar os objetivos.

Um fundamento essencial, que didaticamente simboliza o comprometimento com os mais vulneráveis e também com o equilíbrio 


\section{Revista Brasileira de Bioética}

ambiental do Século XXI, é o que a Bioética de Intervenção denomina de os "4 Ps". O primeiro deles refere-se à prudência frente às possibilidades de que os avanços científico e tecnológico acelerados possam vir a trazer problemas futuros. O segundo " $\mathrm{P}$ " é de prevenção, considerado como o conhecimento a respeito da intervenção antecipada frente a possíveis danos e iatrogenias. O terceiro " $\mathrm{P}$ " diz respeito à precaução diante dos potenciais riscos que não podem ainda ser previstos pelo estado atual do conhecimento. E, por último, o quarto "P", de proteção aos mais frágeis, aos desassistidos (8).

A solidariedade crítica, com foco no genuíno comprometimento do agente em intervenções e ações orgânicas, que busca proporcionar à pessoa-alvo a conquista da real autonomia, livre de qualquer forma de paternalismo, assistencialismo ou autoritarismo, também é entendida pela Bioética de Intervenção como um fundamento relevante. Os indicadores basilares da reciprocidade e alteridade e o agir por meio da reflexão constante da própria prática para alcançar o aperfeiçoamento e o aumento da eficiência para seus propósitos, chamam a atenção para o fato de que o outro deve ser reconhecido como um ser humano igual a cada um de nós e, como tal, goza do mesmo direito à dignidade (17).

Para concluir este rol de considerações fundamentais para a Bioética de Intervenção, ainda em construção, deve-se colocar o imperativo da responsabilidade, conforme descrito por Hans Jonas: "Age de tal maneira que os efeitos de tua ação sejam compatíveis com a permanência de uma vida humana autêntica" (18). Dessa forma, a responsabilidade tem seu escopo significativamente ampliado, não mais exclusivamente de cada ser humano para consigo mesmo, mas de cada ser humano para com todos os demais, inclusive com os que ainda virão a existir. A preocupação concreta é com as gerações futuras, nesta época em que a tecnologia coloca ao alcance dos seres humanos um poder inimaginável, com conseqüências igualmente inimagináveis.

\section{Proposta}

A Bioética de Intervenção não é, de forma alguma, proposta concluída, à qual não cabe reformulações ou acréscimos que agreguem 
consistência a esse pensar bioético. Pelo contrário, é uma proposta em construção com discussão plural e constante. Esta posição é imperativa uma vez que uma corrente fechada, com conceitos e fundamentos esgotados, não seria capaz de gerar respostas dinâmicas a uma realidade em intensa transformação, como a vivida hodiernamente.

Peter Singer, em sua discussão inicial sobre a ética, inspira de certa forma a construção de um pensamento preocupado com a justiça social:

\begin{abstract}
"Imagine-se, agora, que começo a pensar eticamente, a ponto de admitir que os meus próprios interesses não podem contar mais do que os interesses alheios pelo simples fato de serem os meus interesses. No lugar deles, agora tenho de levar em conta os interesses de todos os que serão afetados pela minha decisão. Isso exige que eu reflita sobre todos esses interesses e adote o curso de ação mais apto a maximizar os interesses das pessoas afetadas. Portanto, pelo menos em algum nível de meu raciocínio moral devo escolher o curso de ação que tem as melhores conseqüências para todos os afetados, e fazê-lo depois de examinar todas as alternativas possíveis" (19).
\end{abstract}

Com o objetivo de instrumentalizar de modo particular os países periféricos, especialmente o Brasil, no lidar cotidiano com os conflitos oriundos das questões persistentes e emergentes, enfatizando as questões do âmbito social, a Bioética de Intervenção defende como moralmente justificável, entre outros aspectos: a) no campo público e coletivo: a priorização de políticas e tomadas de decisão que privilegiem o maior número de pessoas, pelo maior espaço de tempo possível e que resultem nas melhores conseqüências coletivas, mesmo que em prejuízo de certas situações individuais, com exceções pontuais a serem discutidas; b) no campo privado e individual: a busca de soluções viáveis e práticas para conflitos identificados com o próprio contexto onde se dá o conflito (9).

Dessa forma, a Bioética de Intervenção almeja a diminuição das diversas iniqüidades existentes na sociedade, por meio de práticas interventivas duras, conforme a própria denominação original desta corrente sugere, hard bioethics. As circunstâncias históricas e cultu- 
rais podem ser consideradas causas das complexas situações verificadas nas relações sociais e, certamente, também contribuem para a explicação da origem de doenças, muitas delas socialmente induzidas. Ao ser reconhecido que o conceito de saúde tem íntima relação com o conceito de qualidade de vida, amplia-se o campo de atuação das correntes bioéticas, apontando o campo social como legítimo para intervenções bioéticas.

"Assim, essa nova proposta teórica propõe uma aliança concreta com o lado historicamente mais frágil da sociedade, incluindo a re-análise de diferentes dilemas, entre os quais: autonomia versus justiça/eqüidade; benefícios individuais versus benefícios coletivos; individualismo versus solidariedade; omissão versus participação; mudanças superficiais e temporárias versus transformações concretas e permanentes" (9).

\section{Reflexões}

Indubitavelmente, a Bioética de Intervenção pode ser considerada como um marco na disciplina de bioética. Essa iniciativa da Cátedra UNESCO de Bioética da Universidade de Brasília contribui para uma nova fase no pensamento bioético em que os países "periféricos" passam a apresentar suas próprias propostas para orientação da resolução de conflitos no campo da moral buscando, assim, um posicionamento mais "central". Este importante passo - ainda que em construção - oferece de modo original uma alternativa adequada às particularidades históricas, culturais e sociais dos países que lidam cotidianamente com o duplo e contraditório fardo imposto pelas questões persistentes e emergentes.

Entretanto, é bem verdade que, da mesma forma que ocorre com as demais correntes de pensamento, existem críticas ao modo como a Bioética de Intervenção orienta a priorização de ações a serem implementadas por instituições, pelo governo ou pela própria sociedade. Ainda que as críticas revelem, muitas vezes, desconhecimento a respeito da proposta ou discordância do modo como a bioética deva ser trabalhada consideramos que uma crítica em particular se mostra pertinente, indicando a necessidade de amadurecimento da proposta inicial. 
$\mathrm{Na}$ abordagem da eqüidade, em tópico anterior, foi expresso que o conceito envolvia o reconhecimento de distintas necessidades de cada indivíduo, em particular para que a coletividade alcançasse um nível de vida com o maior grau de dignidade possível, sendo a igualdade considerada a meta final para a justiça social. Ao elencar como relevante o conceito de eqüidade, a Bioética de Intervenção assume o compromisso de dispensar especial atenção ao indivíduo vulnerável e desempoderado, especificamente, porque como indivíduo (minoria absoluta), não dispõe de força de convencimento suficiente. Assim sendo, falta-lhe a existência ou convivência de um grupo relativamente organizado que dê voz às suas necessidades. Esta é a causa da fragilidade das minorias. Ao expressar como necessárias a priorização de políticas e tomadas de decisões que privilegiem o maior número de pessoas, a Bioética de Intervenção aproxima-se da corrente utilitarista, incorrendo em sério risco de contradição. Nem sempre o interesse da maioria será compatível com o genuíno exercício da eqüidade. Isso é verdadeiro para as mais diversas situações em que são encontrados os conflitos morais, tanto no âmbito de uma instituição hospitalar de uma pequena cidade do interior, como de uma instituição gestora em nível federal.

De certa forma, essa dificuldade se manifesta na organização central dicotômica da proposta que "para o campo público e coletivo, considera-se deste modo" e "para o campo privado e individual, considera-se deste outro modo". O ato de orientar e conciliar tais conflitos demanda uma lapidação da idéia central apresentada pela Bioética de Intervenção, fruto de reflexões e posicionamentos que ainda estão por vir.

A necessidade de serem priorizadas ações concomitantemente benéficas no nível público/coletivo e no privado/individual, que poderia ser alcançado por um critério de beneficência compartilhada, como o Princípio do Bem Comum, está clara. Para ilustrar essa possibilidade, pode-se citar medidas como as campanhas de vacinação, que beneficiam cada uma das pessoas que participam, pois elas passam a ter seu próprio organismo imunizado contra determinado agente infeccioso, além de levar benefício a toda sociedade, pois o risco de futuras epidemias fica significativamente diminuído com o aumento da resistência da população. 


\section{Considerações finais}

Apesar da relativa pouca idade da Bioética de Intervenção, alguns frutos relevantes já estão sendo colhidos. Especial destaque foi a contribuição no momento da redação da Declaração Universal sobre Bioética e Direitos Humanos da UNESCO - Organização das Nações Unidas para a Educação, a Ciência e a Cultura), inter alia, no considerando que declara que "todos os seres humanos, sem distinção, devem se beneficiar dos mesmos elevados padrões éticos na medicina e nas pesquisas em ciências da vida." (20). O considerando registra o posicionamento contrário às tentativas de alteração do texto da $D e-$ claração de Helsinque, sobre a questão do double standard já mencionada neste trabalho. No artigo 14 da mesma Declaração, que trata da responsabilidade social e saúde, considera que "usufruir o mais alto padrão de saúde atingível é um dos direitos fundamentais de todo ser humano, sem distinção de raça, religião, convicção política, condição econômica ou social" (20), também fica comprovada a significaçãod a linha de pensamento da Bioética de Intervenção.

Está claro que a Bioética de Intervenção vem desempenhando papel fundamental para que se adotem padrões éticos de defesa da dignidade do ser humano, promovendo de forma segura e concreta uma vida com qualidade para todos. Todas as pessoas são ao mesmo tempo atores responsáveis da Bioética de Intervenção e objeto de suas reflexões e intervenções.

"Descobrimo-nos portadores de doenças e buscamos resolvêlas individualmente, tentando ignorar que na maioria das vezes elas são frutos de um cotidiano opressor, ditado por uma engrenagem cega que não coloca o ser humano como fim em si mesmo, mas como meio exclusivo para obtenção de lucro. Nossa cegueira, no entanto, não nos exime da responsabilidade. Devemos reconhecer que nossas escolhas cotidianas refletem uma opção ideológica voltada apenas a reproduzir o status quo" (16). 


\section{Referências}

1. Brasil. Senado Federal. Comissão de Assuntos Sociais. Brasil é país com maior evolução em ranking histórico do IDH. Brasília, Brasil. Senado Federal; 2003.

2. Senado Federal. Comissão de Assuntos Sociais. Contrastes do Brasil no RDH 2003. Brasília, Brasil. Senado Federal; 2003.

3. Ministério do Planejamento, Orçamento e Gestão. Instituto Brasileiro de Geografia e Estatística. Evolução e perspectivas da mortalidade infantil no Brasil. Rio de Janeiro, Brasil. Ministério do Planejamento, Orçamento e Gestão; 1999.

4. Garrafa, V. Radiografia bioética de um país - Brasil. Acta Bioethica (OPS/ OMS) $2001 ; 6(1): 165-181$.

5. Fé, IAM. Apresentação. Bioética 1993; 1(1):5.

6. Sociedade Brasileira de Bioética. Quem é quem na Sociedade Brasileira de Bioética. http://www.sbbioetica.org.br/nav/quem.html (acesso em 17/ $\mathrm{Jul} / 2006)$.

7. Brasil. Ministério da Saúde. Conselho Nacional de Saúde. Comissão Nacional de Ética em Pesquisa. Normas para Pesquisas Envolvendo Seres Humanos (Resolução CNS no 196/96). Brasília, Brasil. Ministério da Saúde; 2002.

8. Garrafa, V \& Porto, D. Verbete: Bioética de Intervención. In: Tealdi JC, organizador. Diccionario Latino-Americano de Bioética. Bogotá. In press.

9. Intervention bioethics: a proposal for peripheral countries in a context of power and injustice. Bioethics 200317 (5-6): 399416.

10. Garrafa, V; Oselka, G \& Diniz, D. Saúde pública, bioética e eqüidade. Bioetica 1997; 5 (1):27-33.

11. Berlinguer, G. Bioética cotidiana. Brasília: Editora Universidade de Brasília; 2004.

12. Garrafa, V Inclusão social no contexto político da bioética. Revista Brasileira de Bioética 2005; 1(2):122-132.

13. Verbete: Imperialismo Moral. In: Tealdi JC, organizador. Diccionario Latino-Americano de Bioética. Bogotá. In press.

14. Jones, P \& Palutikof, J. Global temperature record. Climatic Research Unit, 2006. http://www.cru.uea.ac.uk/cru/info/warming (acesso em 19/Jul/2006).

15. Potter, VR. Bioethics, bridge to the future. New Jersey: Prentice-Hall; 1971.

16. Porto, D \& Garrafa, V Bioética de Intervenção: considerações sobre a economia de mercado. Bioética 2005; 13(1):111-123.

17. Selli, L \& Garrafa, V Bioética, solidariedade crítica e voluntariado orgânico.Revista de Saúde Pública 2005; 39(3):473-478.

18. Jonas, H. The imperative of responsibility, in search of an ethics for the technological age. Chicago: The University of Chicago Press; 1985. 


\section{Revista Brasileira de Bioética}

19. Singer, P. Ética Prática. São Paulo: Martins Fontes; 1994.

20. UNESCO. Declaração Universal sobre Bioética e Direitos Humanos; 2005. Em: www.bioetica.catedraunesco.unb.br Acessado em 14/11/2006.

Recebido: 20/09/2006 Aprovado:04/12/2006 